\title{
Discussion to the paper by T. G. Parks
}

\author{
Chairman: Professor J. C. Goligher
}

ChaIRMan. In this very interesting, rather debunking paper, Mr Parks seems to disagree with some of the Scandinavian workers in his physiological studies. It is very interesting to me because our own imperfect studies in our department have made us doubt whether some of their statements were correct or not. Would any surgeon care to comment on this myotomy operation which Mr Parks mentioned and which we've read about, and some of us used?

WATKINSON. We recently heard that Mr Adam Smith of Edinburgh has made some pressure measurements but he felt that it was too early to say whether the pressure rose again. He rather thought that 6 months later the pressure would tend to rise again.

Chairman. We've heard of these studies too, but it wasn't quite clear to me whether the pressures could have been done on the same patient who had the pressures done before the operation. There was a quite different group here with a steadier mean pressure after operation than before. We've been doing pressure before and after but haven't got very far yet; we've done eight myotomies with no deaths, but at a meeting in Edinburgh about 18 months aga on diverticulitis, Michael Riley gave a paper on myotomy which he had claimed as very safe. A number of speakers said they had succeeded in perforating the mucosa and had serious septic complications, and it was not perhaps quite as safe as he would have you believe. But whether it is a good operation or not I don't know, and if there isn't an increased pressure it's difficult to justify.

CoNNELL. Could I make a comment about intraluminal pressures in colonic disease: if one is recording a pressure from the alimentary tract, what it really means is that one has a closed or semi-closed segment in which some change of volume is occurring; it doesn't mean any more than that. If you put a tube with an open end into the bowel there may be activity in the wall without any change in the pressure being detected by that tip. On the other hand, if you put in a small balloon, it's more likely to pick up the activity that occurs in the wall. Now, the narrower the colon becomes, the more likely you are to detect the pressure by your open-tip. So that the pressure recorded from a wide colon and a narrow colon, using the same open-tip and the same amount of wall activity, will be different but this will only reflect the diameter of the gut. Now, using a balloon you won't get quite the same difference, because it detects some wall activity even in a relatively wide lumen. Now studies in diverticular disease have been done largely with open-tip tubes (Arfwidsson, Painter \& Truelove, George Parks and Connell). If you use an open tube, you do get an increase in the intraluminal pressures between normal controls and diverticular disease, in response to food, to morphine and so on. But I am increasingly convinced that this is only telling us that we've got a narrow gutit doesn't tell us anything about the wall activity. Whereas when you use a small balloon, as George
Parks showed just now, there is not the same difference between normals and diverticular disease.

Question. Could I ask Dr Connell: do you think you are describing physiologically in this situation what Williams referred to as contracture?

ConNell. Yes, I think it is in a state of contracture, if you look at it, it is all bunched up. The lumen is convoluted. I accept this. But probably because of this it has not got as much additional function left, it is already acting towards the maximum of its potentiality, so that it just can't resist further stretching. So if you blow up a balloon, as George Parks has done, instead of getting a resistance that a normal muscle gives you, the resultant pressure falls and it compensates pretty fast.

HANCOCK. I'd be very interested to hear of the stool bacteriology on these people on long term succinysulphathiazide particularly in view of Gunn's Ch.M. thesis, that succinysulphathiazide isn't really an efficient agent to clean out the bowel.

Parks. Well now, would one presume that this cleaned out the bowel completely? We have only had them on part-time but it is an effort to reduce the number of acute attacks. But one is doubtful about this, because as Dr Morson will probably agree, a lot of inflammation is peridiverticular. Sulphonamides are not going to have much effect on inflammation outside the bowel.

HANCOCK. Is there not a danger of superinfection, because succinylsulphthiazide doesn't actually give you a sterile bowel? There are lots of organisms which would not be suppressed by it.

Parks. If one used it continually there would be more of a danger of superinfection, but not if you use it for a short period, possibly 1 or $2 \mathrm{~g}$ per day; again we wouldn't claim that this is the correct regime, it is just a possibility; the patients where probably it is worth while trying are those that are not very fit for surgery. Again I think in patients that have some degree of obstruction, and who are elderly and not very fit for surgery, this may be a case for a low-residue diet.

QUESTION. Could I ask whether sigmoid myotomy is frowned upon because it is dangerous or because it is rather flexible? I've done four now, in quiescent ones but not in the really florid state, and I wonder whether one should go on doing it or whether it is to be abandoned.

Chairman. By florid state you mean acute form?

Question. Yes.

ChaIRman. Well, Riley originally referred to this operation for acute cases but he has retracted that since, it does not seem a very simple operation in acute cases. What cases are suitable? I don't know. The best people would be these that hadn't got any diverticula. It is very important that a critical evaluation of the results be made, however difficult. I can't say our patients who have had this operation have all been relieved of their symptoms but many of them have a considerable functional overlay. It is very difficult to assess. 